\title{
Os Mercados e os Dilemas da Autenticidade. Uma análise do Mercado Central de Belo Horizonte ${ }^{1}$
}

Luciana Andrade*

\section{Resumo}

Nas últimas décadas, os mercados de abastecimento, presentes em muitas grandes cidades brasileiras, passaram por uma crise e uma nova significação, em função da concorrência com as recentes formas de comércio a varejo. Vários foram fechados, e outros conseguiram sobreviver a partir da narrativa de lugar autêntico e do seu reconhecimento como patrimônio e atração turística. Este artigo propõe discutir essas novas representações dos mercados, assim como os seus dilemas a partir de um caso ocorrido no Mercado Central de Belo Horizonte. Criado em 1929 e situado na área central da cidade, em 2007, o Mercado ocupou as esferas públicas de discussão quando veio a público o fato de que uma antiga loja de alimentos a granel, fechada por decisão de seus proprietários, seria substituída por outra de uma grande rede de eletroeletrônicos.Com base nesse episódio discutem-se as dimensões patrimoniais e turísticas dos atuais mercados ancoradas no discurso da autenticidade. Para tanto, ele se estrutura em três partes. Uma primeira analisa a construção de uma narrativa de autenticidade em torno de bens urbanos, a segunda situa historicamente o Mercado Central, e a última analisa a polêmica desencadeada a partir do fechamento e substituição de uma das suas lojas.

\section{Palavras-chave}

Mercado. Autenticidade. Patrimônio.

\section{Abstract}

In recent decades the supply markets, in many large cities, have gone through a crisis and through a new significance due to rivalry with newer forms of retail trade. Several were closed and others managed to survive from an authentic place's narrative and from their recognition as heritage and tourist attraction. This article aims to discuss these new representations of the

\footnotetext{
${ }^{1}$ Agradeço aos valiosos comentários dos pareceristas. Este artigo dialoga com pesquisa em curso financiada pelo Conselho Nacional de Desenvolvimento Científico e Tecnológico (CNPq) com bolsa de Produtividade e pela Fundação de Amparo à Pesquisa do Estado de Minas Gerais (FAPEMIG).

* Luciana Teixeira de Andrade é Socióloga, Professora do Departamento de Ciências Sociais da Pontifícia Universidade Católica de Minas Gerais (PUC - Minas). É também Pesquisadora do Observatório das Metrópoles. E-mail: lucianatandrade1@gmail.com.
} 
markets and their dilemmas from the case occurred in the Central Market of Belo Horizonte. Created in 1929 and located in the central area of the city, in 2007, the market held attention of the public discussion sphere when it became known that the place where there used to be an old store that sold food in bulk, and which had been closed by its owners decision, would be replaced by another store, from a large eletronics retail chain. From this episode we discuss the heritage and touristic dimensions of current markets anchored in the authenticity speech. Therefore it is structured in three parts. The first analyzes the construction of an authenticity narrative around urban goods, the second historically situates the Central Market and the last analyzes the controversy triggered from the closure and replacement of one of its stores.

\section{Keywords}

Markets. Authenticity. Heritage.

\section{Introdução}

Nas últimas décadas do século passado, o mercado global de varejo das grandes cidades passou por mudanças profundas, com a disseminação dos hiper e supermercados, dos shopping centers e das grandes redes de lojas. Essas mudanças atingiram de formas diferenciadas os mercados de abastecimento, cujas marcas são a diversidade de produtos ofertados em pequenas lojas ou bancas por comerciantes individuais. ${ }^{2}$ Parte deles não conseguiu sobreviver à concorrência, parte se renovou e continua a funcionar, com maiores ou menores dificuldades de adaptação aos novos tempos, enquanto outros surgiram acompanhando uma nova cultura de consumo, como os mercados de produtos orgânicos (BROMLEY, 1998; WATSON; STUDDERT, 2006; ZUKIN, 2008). ${ }^{3}$

Em muitas cidades brasileiras (BITAR, 2016; SILVA, 2015), como no caso

\footnotetext{
${ }^{2} \mathrm{Na}$ Europa a literatura aponta o século XIX como o período no qual esse tipo de mercado urbano prolifera nas grandes e médias cidades; já no Brasil esse fenômeno ocorre a partir do final do século XIX (SILVA, 2015).

${ }^{3}$ Essas são apenas algumas tendências dos atuais mercados. Uma análise que se pretendesse mais abrangente teria que contemplar a diversidade dos mercados e a tradição diferenciada das cidades, com distintas estratégias diante dos efeitos homogeneizantes da globalização do comércio.
} 
de Belo Horizonte aqui analisado, os mercados surgiram como uma decisão da administração pública para garantir o abastecimento de alimentos. Atualmente, alguns permanecem públicos; outros foram privatizados ou funcionam em arranjos mistos. Uma transformação mais recente se deu no campo das práticas e significados. De espaço de abastecimento de bens de primeira necessidade e voltados preponderantemente para o consumo local, os mercados foram investidos de significados socioculturais, turísticos e patrimoniais, justamente no momento em que sua existência começou a ser ameaçada. Essas mudanças tiveram vários desdobramentos, entre os quais o seu reconhecimento e valorização como espaços públicos de interações sociais face a face, distintas da impessoalidade preponderante nas formas hegemônicas do comércio de varejo; o seu valor turístico, em função da representação das culturas locais, e o seu reconhecimento como patrimônio imaterial.

O que me motivou a escrever este texto foram os fatos desencadeados em 2007, com a notícia de que seria aberta no Mercado Central de Belo Horizonte uma loja de uma grande rede de eletroeletrônicos. A partir de então, as mudanças que já vinham ocorrendo no Mercado passaram a ser discutidas em distintos foros, como internet, meios de comunicação locais e instâncias de proteção ao patrimônio.

À época eu participava do Conselho Deliberativo do Patrimônio Cultural de Belo Horizonte (CDPCBH) como membro da sociedade civil e fui designada para apreciar um pedido do Ministério Público do Estado de Minas Gerais, que tinha sua origem nas reações da sociedade civil diante da notícia da inauguração da referida loja de eletroeletrônicos. Essa loja seria aberta onde antes havia uma mercearia que comercializava produtos alimentícios a granel, fechada um tempo antes por decisão de seus antigos proprietários, que, já idosos, não tiveram mais condições de mantê-la em funcionamento. O pedido do Ministério Público recomendava à Secretaria Municipal Adjunta de Regulação Urbana que se abstivesse da emissão de alvará para qualquer loja no interior do Mercado, sem a prévia manifestação do CDPCBH. Requisitava, ainda, que a Gerência de Patrimônio Histórico Urbano (GEPH) efetuasse vistoria no Mercado Central e enviasse ao Ministério Público, num prazo de 45 dias, relatório técnico indicando os estabelecimentos que estivessem em desconformidade com a proteção ao patrimônio cultural, em seus aspectos material e imaterial, indicando ainda as medidas necessárias para a sua adequação.

O pedido era em parte inusitado, uma vez que o Mercado não era um 
bem protegido pelo $\mathrm{CDPCBH}$, havendo apenas uma indicação para a sua proteção, como será explicitado adiante.

Como desdobramento do parecer, passei a integrar uma comissão de representantes do CDPCBH e do Mercado, com o objetivo de se chegar a um acordo sobre a sua proteção, uma vez que a associação dos lojistas do Mercado vinha reagindo contrariamente a qualquer tentativa de proteção.

Esses acontecimentos também repercutiram na Superintendência Regional do Instituto do Patrimônio Histórico e Artístico Nacional (Iphan). Com representação no CDPCBH e uma política em curso de proteção a outros mercados e feiras, o Iphan se mobilizou em prol da proteção ao Mercado. Entre as ações desse órgão, que objetivava fazer o registro do Mercado como bem imaterial, acompanhei um seminário realizado nas suas dependências, cuja intenção era sensibilizar os diretores da associação e demais comerciantes.

Dois anos antes concluí a orientação de uma dissertação de mestrado sobre o Mercado (COSTA, 2006), posteriormente transformada em livro (COSTA, 2007). As fontes deste artigo foram, portanto, a minha experiência com as tentativas empreendidas de preservação do Mercado, a proximidade com o tema em função da orientação da dissertação de mestrado, visitas ao Mercado para observação da sua rotina, consulta aos trabalhos acadêmicos produzidos, assim como o próprio site do Mercado e de algumas empresas relacionadas com o seu processo de proteção.

O texto se divide em três partes. A primeira se dedica a uma apresentação das narrativas de autenticidade vinculadas à vida urbana. A segunda apresenta um pouco da história do Mercado e de suas transformações ao longo do tempo. A terceira analisa a polêmica em torno da nova loja e as tentativas frustradas de proteção do Mercado.

\section{Os Dilemas da Autenticidade}

A autenticidade vem sendo estudada e problematizada como uma moderna categoria do pensamento que pode ser aplicada a pessoas e coisas; e a busca por experiências autênticas como uma característica da sociedade moderna (TRILLING, 1971; HANDLER, 1986; GONÇALVES, 1988; ZUKIN, 2010). A autenticidade já foi um patrimônio dos museus, mas atualmente é também associada a experiências cotidianas nas quais formas tradicionais de viver, produzir e consumir estejam presentes (McCANNELL, 1973; MULLINS, 2012; ZUKIN, 2012). 
O que está em questão nessas concepções é a dimensão não aurática da autenticidade inspirada em Walter Benjamin (1980) e, portanto, mais centrada na experiência do que na contemplação, como ocorria com as obras de arte originais ${ }^{4}$ Segundo Gonçalves (2012), a autenticidade não aurática não mantém um vínculo orgânico com o passado e, dessa forma, abre espaço para recriações, para novos usos e sentidos, como se observa na renovação de centros históricos para usos atuais e turísticos.

Com o patrimônio imaterial ou intangível (TAMASO, 2005; ARANTES, 2009), houve um deslocamento do foco da identidade nacional, tradicionalmente construída como única e autêntica, para a incorporação de novas práticas e atores. ${ }^{5}$ Consequentemente, emergem distintas formas de conflito e de negociações (FONSECA, 2003).

O patrimônio, no entanto, não é o único campo em que a autenticidade é debatida. MacCannell (1973), por exemplo, analisa a procura pela autenticidade como um fenômeno da época moderna presente em alguns tipos de turistas que almejam uma experiência ao mesmo tempo real e autêntica. Uma forma de consegui-la é adentrar as regiões de fundo, ou os bastidores, como as definiu Erving Goffman (1999). Ao assim fazerem, os turistas recusam o papel de simples audiência, situação na qual apenas a fachada é acessível. ${ }^{6}$

Sharon Zukin chama a atenção para os vários sentidos da autenticidade. Um deles articula autenticidade a algo original porque novo; já nos estudos vinculados aos processos de valorização de partes antigas da cidade prevalece o sentido de algo original porque antigo e histórico. Esse último sentido vincula autenticidade a um tipo de cultura urbana que valoriza a convivência em espaços tradicionais e históricos das cidades, sejam eles comerciais (ZUKIN, 2012), residenciais ou mistos (ZUKIN, 2010). Zukin

\footnotetext{
${ }^{4}$ Segundo Walter Benjamin, a reprodutibilidade técnica tira dos objetos a sua aura, ou seja, "a aparição única de uma coisa distante por mais perto que ela esteja" e substitui a existência única (a aura) pela sua reprodução (BENJAMIN, 1980).

${ }^{5}$ Segundo o decreto que instituiu no país a proteção aos bens imateriais, esses podem ser de quatro tipos: saberes, celebrações, formas de expressão e lugares. Isso acarretou uma significativa ampliação dos bens passíveis de proteção.

${ }^{6}$ MacCannell (1973) adverte que nem todos os turistas se interessam pelas regiões dos bastidores, uma vez que o turismo é um fenômeno plural, além de uma entre várias outras atividades em que a busca da autenticidade se faz presente.
} 
(2012) também não compartilha de uma visão aurática da autenticidade como um valor intocável, ao contrário, analisa-a como uma construção baseada nos novos valores da cultura urbana.

Ao se referir às manifestações pela preservação da autenticidade, Zukin (2009) diferencia dois tipos de ação. Em um deles a autenticidade se conecta à retórica do crescimento, o que pode resultar em dinâmicas de expulsão de pessoas e de suas práticas. Em outro, a autenticidade é politizada em uma plataforma de coalizões amplas que reivindica o direito moral de se viver e trabalhar em um espaço, evitando assim as expulsões.

O estudo de Sharon Zukin (2012) sobre uma rua comercial de Amsterdam interessa-nos, pois, apesar das diferenças (trata-se de uma sofisticada rua comercial), as pequenas lojas e a relação de conhecimento pessoal entre os comerciantes e seus fregueses a aproximam do Mercado Central de Belo Horizonte, apresentado a seguir.

No seu estudo sobre a Ultrechtsestraat, Zukin (2012) identificou no espaço e nas interações entre os comerciantes e seus clientes um exemplo de patrimônio cultural vernacular e intangível, ligado à cultura do dia a dia, em oposição ao patrimônio monumental e oficial. A importância desses espaços deve-se à sua capacidade de evocar o sentimento de pertencimento social, de identidade local e de continuidade histórica. Sentimento nutrido pelo longo tempo de existência das lojas e pelas relações face a face entre clientes e comerciantes.

Na perspectiva sociológica, são essas questões de pertencimento e de integração social que estão na base dos estudos sobre as mudanças que ocorrem nos espaços de moradia, como os bairros; de consumo, como os mercados e de lazer, como os espaços públicos.

Mais recentemente, os estudos sobre a gentrificação vêm mostrando uma nova face dessas mudanças e da questão da integração social num contexto de mercantilização das cidades (RIBEIRO; SANTOS JÚNIOR, 2015) e de espetacularização dos seus patrimônios (LEITE, 2010). A gentrificação, identificada inicialmente por Ruth Glass (1964) nos bairros londrinos, diz respeito à expulsão de grupos sociais dos seus espaços de moradia e/ou consumo, decorrente da entrada, nesses mesmos espaços, de grupos sociais com maior poder econômico e cultural (SMITH, 1996, BIDOU-ZACHARIASEN, 2007; SLATER, 2011; LESS et al., 2008; RUBINO, 2009). A autenticidade é uma das narrativas presentes na valorização desses espaços. 


\section{O Mercado Central de Belo Horizonte}

O Mercado Municipal de Belo Horizonte foi inaugurado em 1900, três anos após a inauguração da cidade, como uma iniciativa da prefeitura, visando ao abastecimento da população com produtos hortifrutigranjeiros. Sua primeira sede ficava na área central, mais especificamente na Avenida Afonso Pena, onde hoje existe o Terminal Rodoviário. Nessa época a cidade contava com 13.472 habitantes (COSTA, 2007). O Mercado foi um entre vários outros tipos de serviço que precisaram contar com a ação do Estado não apenas para a sua regulação, mas para a sua criação e organização. Destaque-se ainda a preocupação da municipalidade com o controle do comércio ambulante nas ruas da cidade e com as normas de higiene que deveriam reger uma cidade moderna como a planejada capital do estado (ANDRADE, 1987). Seu aspecto nos primeiros anos mais se assemelhava às atuais feiras livres, com os produtos expostos em tabuleiros e sem cobertura. Por isso, enfrentava problemas com a comercialização dos alimentos, principalmente aqueles relacionados à organização e à higiene. Isso motivou sua primeira reforma em 1913, que buscou organizar a venda de produtos perecíveis, como carnes e peixes. No final da década de 1920, as instalações do Mercado não comportavam mais a demanda de uma população que ultrapassava cem mil habitantes.

Em 1929, o Mercado foi transferido para um terreno de $14.000 \mathrm{~m}^{2}$ em outra parte da área central da cidade, nas proximidades da Praça Raul Soares, onde continua até os dias de hoje. Na metade da década de 1940, Costa (2007) relata que a prática dos prefeitos de liberarem vagas para os seus afilhados políticos e a abertura do comércio para outros produtos que não os tradicionais alimentícios ensejaram em alguns comerciantes antigos o sentimento de que o Mercado estava se descaracterizando. Em 1964, diante do seu crescimento e dos problemas relacionados à sua gestão, a prefeitura alegou não ter mais como administrá-lo e colocou o seu terreno à venda. Com a finalidade de mantê-lo, os lojistas criaram uma cooperativa, que adquiriu o terreno da prefeitura. Durante a negociação, foi-lhes exigida a construção de uma cobertura. Desde então, o Mercado passou a ser fechado, teve seu nome alterado para Mercado Central e é administrado por uma associação dos comerciantes eleita a cada quatro anos (COSTA, 2007; FILGUEIRAS, 2006).

Durante toda a sua história, o Mercado passou por várias reformas em sua estrutura física, como a substituição dos tabuleiros por lojas, ou os 
chamados boxes. Foi também construída uma cobertura que mais adiante passou a ser utilizada como estacionamento. Atualmente, o Mercado conta com cerca de 400 lojas no andar térreo, e o superior é destinado a um estacionamento com aproximadamente 400 vagas, capela e sede da administração. Entretanto, as suas principais alterações não foram físicas.

Com o surgimento dos supermercados e depois dos chamados sacolões, voltados para a venda de verduras e legumes por um preço fixo e, em geral, mais baixo do que os praticados no Mercado Central, esse tipo de produto foi significativamente reduzido no Mercado. Paralelamente, surgiram as lojas de produtos naturais, de suplementos alimentares e de produtos para musculação. Já os bares cresceram em unidades e em números de frequentadores.

Não sendo mais a principal instituição de abastecimento da capital, o Mercado foi conquistando outro lugar na vida da cidade, atraindo novos frequentadores para o consumo de produtos dificilmente encontrados nos supermercados, mas também para atividades ligadas ao lazer e ao turismo. Essa atratividade se relaciona principalmente com a manutenção de um comércio tradicional, ainda que não se deva desconsiderar o papel das novas lojas no atendimento das atuais necessidades dos consumidores locais e dos turistas. Um exemplo são os caixas eletrônicos.

Em 2017, o site do Mercado Central listava mais de 400 lojas divididas em 81 categorias. Entre o comércio tradicional e de produtos não facilmente encontrados nas grandes lojas do comércio de varejo estão aqueles de diferentes regiões do estado de Minas Gerais, como os queijos (36 lojas), artesanato (32 lojas), ervas e raízes (22), temperos e condimentos (17), cachaças (4), fumo de rolo, comercializado nas tabacarias (5), além de produtos religiosos (5), esotéricos (2), para capoeira (1), frutas e outros produtos alimentícios regionais não cultivados em grande escala. Entre os novos destacam-se os produtos para musculação (11), acessórios/telefonia (2), agência de turismo (1) e caixas eletrônicos.

Se alguns produtos perderam espaço no Mercado, os bares se expandiram a ponto de a direção não permitir a abertura de novos. ${ }^{7}$ E, ainda que alguns

\footnotetext{
${ }^{7}$ Segundo os diretores do Mercado, há uma preocupação em manter a diversidade de produtos comercializados, evitando-se a expansão desequilibrada de certas lojas e ramos. Entre essas estão os bares. Apesar de seu número não ser muito alto (11), a aglomeração de pessoas no seu entorno (os corredores do Mercado) gera problemas de circulação, principalmente nos dias de grande movimento, como os finais de semana. Para tanto, foram colocadas barreiras físicas que delimitam o espaço reservado aos fregueses.
} 
bares tenham se adaptado à forma de restaurantes com mesas e cadeiras, a maioria ainda mantém a antiga forma de atendimento aos fregueses (em pé) no balcão, o que gera um clima informal, propiciando a interação entre os fregueses, que ficam muito próximos uns dos outros.

Além das mudanças na organização do mercado de varejo e nos hábitos e costumes dos consumidores, algumas lojas enfrentam o problema de continuidade quando os herdeiros não se interessam pela atividade comercial. Nesses casos, a venda pode implicar uma mudança de ramo, como aconteceu com o caso analisado na terceira parte deste artigo.

Com funcionamento de segunda a sábado de 7 às 18 horas e aos domingos e feriados de 7 às 13 horas, o Mercado ocupa um quarteirão inteiro na área central da cidade, com sete portões que facilitam o seu acesso por importantes e movimentadas ruas do centro da cidade. ${ }^{8}$

Alguns dados da pesquisa realizada por Costa (2006) com 700 frequentadores do Mercado $^{9}$ mostram outras dimensões da diversidade social. Em relação às faixas etárias, há uma distribuição bastante equitativa entre os entrevistados, o que mostra a capacidade do Mercado de atrair diferentes públicos, com menor participação das crianças e adolescentes. Para os primeiros, há uma parte de animais domésticos que desperta muito a atenção; para os adolescentes, o Mercado não oferece grandes atrativos. Em relação à escolaridade, a pesquisa detectou uma presença expressiva de pessoas com nível superior, 33\%, mas a educação fundamental e média estão bem representadas, respectivamente, 22\% e 44\%. Quanto à periodicidade da frequência, há tanto aqueles que o frequentam diariamente (14\%), semanalmente (34\%), quinzenalmente ou mensalmente $(26 \%)$ e ocasionalmente (26\%). Isso revela diferentes hábitos, desde os pertinentes aos que ali vão à procura dos produtos do dia a dia, até os que só o frequentam ocasionalmente, provavelmente em busca de produtos especiais e/ou de lazer. Hipótese reforçada pela resposta a outra pergunta,

\footnotetext{
${ }^{8}$ A área central da cidade abriga hoje um comércio menos sofisticado, dado o deslocamento do comércio mais sofisticado para a região da Savassi, outra centralidade surgida na década de 1970, e para os shopping centers. O fato de o Mercado estar situado na área central favorece a frequência de grupos de menor poder aquisitivo e de diferentes regiões da metrópole, uma vez que as principais linhas de ônibus da cidade e da região metropolitana passam pelo Centro.

${ }^{9}$ A pesquisa foi realizada durante os meses de dezembro de 2005 e janeiro, abril e maio de 2006 em diferentes pontos do Mercado e em diferentes dias e horários (COSTA, 2006).
} 
sobre o motivo da visita: $54 \%$ responderam fazer compras e $44,2 \%$ para lazer e encontrar amigos.

O que se depreende desses dados é que o Mercado conseguiu sobreviver à concorrência das novas formas globalizadas do comércio de varejo, abrindo-se para algumas inovações, mas mantendo a tradição das lojas individualizadas, com distintos tipos de produto, o que lhe confere ao mesmo tempo diversidade e unicidade, importantes fatores para a atração da população local e dos turistas que visitam a cidade. ${ }^{10}$

Em relação às representações do Mercado, encontradas no seu site e em guias e blogs turísticos, destaca-se a ideia do Mercado como uma síntese da cultura mineira e, por isso mesmo, como um lugar autêntico. Ir ao Mercado é uma forma de conhecer e experimentar a pluralidade mineira, por meio de produtos e manifestações culturais (artesanato, culinária) de diferentes partes do estado.

Quem quiser conhecer e vivenciar a diversidade e a pluralidade cultural de Minas Gerais, em um único espaço, deve visitar o "Mercado Central" - onde será possível respirar a cidade, conhecer, fruir e comprar objetos característicos da cultura mineira. Caminhar pelos corredores do Mercado e pela região que circunda esse espaço significa percorrer parte importante da história e da cultura mineira.

(Site da Belotur - Disponível em: http:/ / www.roteirosdebh.com. br/?id=66\#lnk-roteiro).

Tal narrativa também se faz presente nas propagandas do Mercado. Em 2005, foi lançada a campanha: Tá procurando? Vá ao Mercado Central que você encontra! (COSTA, 2007). Seu site veicula distintas chamadas, nas quais a combinação entre tradição e turismo é a mais recorrente: "Tem coisas de Minas que, reunidas, só se vê no Mercado Central de BH ou, ainda: "'queijim' de tudo quanto é tipo e sabor..." (http://www.mercadocentral.com.br/). Na

\footnotetext{
${ }^{10}$ Belo Horizonte nunca foi considerada uma cidade com grandes atrativos turísticos, mas como local de passagem para as cidades históricas e, mais recentemente, para o museu do Inhotim. Pesquisas realizadas pela agência oficial de turismo da cidade, a Belotur, mostram que a inauguração de vários museus, o festival de Comida de Buteco e o renascimento do carnaval vêm atraindo um maior número de turistas, a maioria do próprio estado, com o objetivo de lazer, superando, pela primeira vez em 2015, o turismo para negócios. Entre as atrações da cidade, o Mercado figura como uma das principais, tanto no guia da Belotur, como no TripAdvisor, Guia BH, entre vários outros.
} 
área do estacionamento, alguns outdoors divulgam as seguintes mensagens, sempre precedidas da expressão Mercado Central:

Comércio, turismo e cultura, Bom lugar para se conviver / O ponto de encontro dos mineiros / Temperos, aromas, sabores, crenças, cores: todas as características mais marcantes da cultura mineira dão charme e muita personalidade ao mercado mais querido de Belo Horizonte.

Em blogs e guias turísticos, a autenticidade aparece vinculada à própria concepção da forma mercado como um lugar de consumo contraposto aos supermercados e aos shopping centers e como síntese da cultura mineira. Nesse sentido, o Mercado é um local único, pela capacidade de reunir a diversidade presente no estado, mas também porque os produtos dessas distintas partes do estado são considerados como os mais representativos da cultura mineira.

No blog de viagens de uma jornalista, estabelecimentos como o Mercado Central aparecem como um exemplar dessa categoria:

Mercados são os meus lugares preferidos nas cidades. São uns dos lugares obrigatórios nas minhas viagens, pois é neles que eu procuro entender como funciona a dinâmica local, os hábitos das pessoas e o que elas comem! Fujo dos mercados muito turísticos e procuro o que há mais de regional na cidade - quase toda aglomeração de pessoas tem um mercado, afinal, desde antes da invenção do supermercado impessoal, sempre foi preciso comprar comida e coisas do dia a dia em algum lugar.

(Eu sou atoa. Dicas para o viajante independente - Grifos meus).

Em seguida, ela sugere a compra de alguns produtos considerados como representativos do gosto autêntico de Minas: São eles: queijo, cachaças, biscoitos, artigos para casa típicos do estado e doces regionais (Eu sou atoa. Dicas para o viajante independente).

Essa contraposição do Mercado, considerado como um lugar autêntico, com os shopping centers e supermercados é recorrente nos blogs e nos comentários dos leitores. Apesar de a maioria elogiar o Mercado e seus produtos, há também algumas avaliações críticas que acusam o mercado de estar perdendo o seu caráter com a entrada das novas lojas:

“O Mercado Central está morrendo. Precisamos salvá-lo. Antes que seja tarde. Mercado é lugar de se comprar comidas, bebidas e 
bugigangas. Não é lugar de se comprar suplementos alimentares industrializados nem móveis e eletroeletrônicos de grande porte. O mercado já foi maravilhoso e imperdível".

(Comentário postado no web site Férias Brasil em setembro de 2008).

O blog turístico Guia BH destaca a diversidade de produtos, laticínios e doces mineiros, artesanato regional, ervas medicinais e a comida: "(...) a comida típica mineira servida nos bares e restaurantes populares" (Guia $\mathrm{BH}$, Mercado Central). Outro blog turístico, Sou BH, destaca o que chama de atmosfera mineira: "Ao passar pelos corredores do Mercado Central, é possível degustar comidas típicas, assistir a manifestações artísticas, ver artesãos criando novas peças...enfim, viver um pouco a atmosfera mineira" (Sou BH).

A autenticidade aparece nessas narrativas como algo ligado à tradição do estado, mas que prima pela raridade, por se tratar de formas de fazer artesanais, algumas em vias de extinção. Esse é um dos fatores que faz o Mercado Central ser representado como um lugar autêntico em contraposição a outras formas de comércio tidas como inautênticas por comercializarem produtos industrializados e globalizados. ${ }^{11}$

Ir ao Mercado propicia uma experiência gustativa, olfativa e visual em função da forma como os produtos são apresentados, muitos deles sem embalagens plásticas e facilmente acessíveis aos olhos e ao consumo no local. Propicia também o contato com uma diversidade de pessoas e a possibilidade de interação social com os comerciantes e outros consumidores (ROCHA; OLIVEIRA, 1997; COSTA, 2006).

Não é intenção deste artigo investigar a origem dessa narrativa de lugar autêntico. O mais provável é que diversos discursos de diferentes fontes, institucionais ou não, contribuíram para a sua existência. Importante registrar que o Mercado já foi objeto de duas dissertações de mestrado aqui citadas (FILGUEIRAS, 2006; COSTA, 2006), de artigos acadêmicos (ROCHA; OLIVEIRA, 1997; NETTO; DINIZ, 2004), de várias monografias de estudantes de graduação, principalmente de turismo, de um livro escrito pelo compositor Fernando Brant (2004), além de vários artigos em jornais e de figurar em vários guias e blogs sobre a cidade.

\footnotetext{
${ }^{11}$ Nos últimos anos apareceram na cidade cafeterias, queijarias e cachaçarias, para citar apenas alguns exemplos, voltadas para o comércio de produtos antes só encontrados no Mercado.
} 
Além disso, a narrativa da autenticidade, baseada na cultura mineira e reunida em um só e único lugar, é hoje parte essencial do marketing do mercado.

\section{A Proteção ao Mercado}

Em 2004, foi promulgada em Belo Horizonte uma lei municipal para proteção dos bens de natureza imaterial. A intenção do vereador proponente era inaugurar a aplicação da lei com o registro imaterial do Mercado Central, mas sua proposta foi rejeitada pela diretoria da associação dos lojistas do Mercado. Nesse mesmo ano, o Conselho Deliberativo do Patrimônio Cultural do Município de Belo Horizonte (CDPCMBH) aprovou a abertura de estudos do Conjunto Urbano da Praça Raul Soares, Avenida Olegário Maciel e adjacências. A partir desses estudos, a Gerência de Patrimônio indicou o tombamento das edificações consideradas polarizadoras do conjunto, entre elas o Mercado Central, mas, em razão da resistência da associação de lojistas e de outras questões administrativas internas à prefeitura, o processo não avançou.

Em sua dissertação, Filgueiras (2006) identificou, a partir de entrevistas com membros da diretoria da associação e com os lojistas, uma disputa interna em relação ao futuro do Mercado. O grupo que compunha a diretoria à época da sua pesquisa e também do conflito que será aqui relatado era a favor da modernização. Ainda que se apresentasse como tendo uma posição intermediária, era visto, pelos defensores da manutenção da tradição, como modernizadores. Apostavam na abertura do Mercado à renovação e eram contrários a qualquer relação com o poder público, considerando-a como uma ingerência num bem privado. Já o outro grupo apostava no turismo e era mais aberto a uma aproximação com o poder público. De toda forma, havia o argumento de que qualquer mudança mais significativa no Mercado deveria passar pela decisão da associação, mas, em alguns casos, como o que se relatará a seguir, uma demanda pode parar na diretoria e não chegar até o conjunto dos lojistas.

Em 2007, a discussão sobre a necessidade de proteção ao Mercado voltou à tona com a notícia de que uma das suas mais antigas e tradicionais lojas, uma mercearia que vendia alimentos a granel, já fechada à época, seria substituída por outra de uma grande rede de eletroeletrônicos, muito conhecida na cidade, em especial por suas propagandas na televisão. $\mathrm{O}$ espaço da antiga loja era o maior espaço contíguo disponível no Mercado, 
com $111 \mathrm{~m}^{2}$. A reação se dirigiu à nova loja, vista como moderna e do ramo dos eletroeletrônicos, atributos que desafiavam as ideias de tradição e autenticidade do Mercado, como discutido anteriormente. Segundo mensagem que circulou nas redes sociais: "É consenso geral que uma loja de eletroeletrônicos descaracteriza o caráter do mercado - descaracterização que acontece de forma lenta, porém contínua. E que agora será escancarada pelo caráter moderno inerente a uma loja de eletroeletrônicos" ${ }^{12}$ Além disso, havia o temor de que com essa nova loja se abrisse a possibilidade de entrada de outras semelhantes, o que poderia levar o Mercado a perder as suas características de um aglomerado de pequenas lojas e se transformar em um shopping center, como mostra a seguinte passagem retirada do mesmo e-mail. "Sabemos (...) que, com o precedente, outros comércios semelhantes serão ali criados, transformando, brevemente, aquele local em outro SHOPPING CENTER" (Grifo no original).

Além desse e-mail, que conclamava a população a boicotar a loja, o fato ensejou outras reações, como a intervenção do Ministério Público, que resultou na suspensão temporária do alvará de instalação da nova loja até a manifestação favorável do CDPCMBH. Já a associação dos lojistas do Mercado, como vimos, manifestou-se contrariamente ao tombamento, assim como a qualquer intervenção pública nos seus negócios.

Em reunião do CDPCBH, realizada em 26 de março de 2008, o parecer dizia que o Conselho não tinha como se manifestar sobre uma loja em específico e propunha a continuidade do processo de tombamento aberto em 26 de dezembro de 2007, assim como a manutenção do diálogo com a associação dos lojistas. Diante do impasse e seguindo a sugestão de diálogo do parecer, foi formada uma comissão de conselheiros e membros da associação de lojistas do Mercado para a condução do processo. Era consenso, entre os conselheiros e os técnicos da Gerência de Patrimônio, que o Mercado deveria ser protegido como um bem de natureza imaterial. Essa opção justificava-se em razão de o seu principal patrimônio ser identificado com os produtos ali comercializados, como também com a sociabilidade que ele proporciona, ainda que o espaço não devesse ser desconsiderado. Havia igualmente uma preocupação com a preservação

\footnotetext{
${ }^{12} \mathrm{O}$ conteúdo desse e-mail ainda pode ser encontrado em alguns grupos na internet: https://br.groups.yahoo.com/neo/groups/batistao96/conversations/topics/202; http://abanja.blogspot.nl/2008/02/como-sabido-estava-fora.html ; e https://br.groups.yahoo.com/neo/groups/psicologosufmg/conversations/messages/758.
} 
do comércio em pequenos boxes, o que permite a diversidade de produtos e de comerciantes. A possibilidade de junção de lojas poderia significar a abertura para a entrada de grandes lojas e a consequente expulsão dos pequenos comerciantes.

As reuniões da comissão, no entanto, não foram bem-sucedidas, dado que a diretoria da associação de lojistas não aceitava nenhuma forma estatal de proteção. Posteriormente, o órgão nacional de patrimônio, o Iphan, iniciou um processo de aproximação com a diretoria da associação com o intuito de fazer o inventário do Mercado como patrimônio imaterial, como já havia feito com a feira de Caruaru em Pernambuco e outros mercados regionais. O projeto Mercado Central: memórias e perspectivas, desenvolvido pela superintendência do Iphan em Minas Gerais, objetivava o registro das memórias que conformavam o Mercado como um lugar de referência e a sua salvaguarda como bem cultural. Para tanto, realizou entrevistas com lojistas, promoveu um seminário no próprio Mercado Central, tratando do patrimônio imaterial e de outras experiências de proteção de mercados no Brasil, como forma de sensibilizar os lojistas. No entanto, diante da resistência da diretoria, os técnicos do Iphan nem chegaram a apresentar a proposta aos associados. Como ocorrido com a comissão municipal, os trabalhos não progrediram, porque a proteção ao patrimônio imaterial, diferentemente do patrimônio material, só se realiza com a concordância daqueles mais diretamente envolvidos com o bem a ser protegido. Como resultado, o Iphan publicou um livro/CD com os depoimentos coletados nas entrevistas (IPHAN, 2010).

Nesse momento, a loja da rede de eletroeletrônicos já estava instalada, mas de uma forma diferente das suas outras filiais na cidade. Na vitrine, em vez de cartazes anunciando os preços, foram colocados eletroeletrônicos antigos. Um ano depois, a loja fechou as suas portas, alegando baixo retorno de vendas, comparativamente às suas outras lojas em shopping centers e em outras partes da cidade. No lugar foi instalada, em 2012, uma loja de uma rede local de vinhos, o que não chegou a gerar reações. O interessante aqui é que as duas lojas fazem parte de redes, ainda que a de vinhos, até mesmo em função do produto que comercializa, seja relativamente menor (seis lojas em Belo Horizonte) do que a de eletroeletrônicos (280 lojas em três regiões do Brasil, Sudeste, Nordeste e Centro-Oeste). Apesar de o vinho não fazer parte dos produtos tradicionalmente comercializados no Mercado, até porque não é um produto regional, diferentemente da cachaça, por exemplo, a sua aceitação evidencia como os valores da autenticidade não 
aurática possibilitam essa abertura à negociação.

Um ano depois, pelos mesmos motivos da loja de eletroeletrônicos, a casa de vinhos fecharia suas portas. A solução foi dividir o espaço em três lojas: uma peixaria, uma loja de produtos naturais e outra de peças decorativas. Interessa agora compreender as reações contrárias à instalação da loja de eletroeletrônicos diante dos valores da autenticidade.

A reação causada pela instalação da loja da rede de eletroeletrônicos tem a ver com uma incompatibilidade de representações entre os valores associados a essa loja e a produção de autenticidade vinculada ao Mercado que, por sua vez, não colidiu com a loja de vinhos. A rede de eletroeletrônicos constrói sua imagem a partir da ideia de preços baixos e novidades. $\mathrm{O}$ preço baixo carrega o valor da indistinção: ele não seleciona, ao contrário, procura a todos incluir. Já o Mercado tem fama de ser caro. O Mercado comercializa produtos artesanais e pouco padronizados. $\mathrm{O}$ marketing da loja de eletroeletrônicos é bastante agressivo sonora e visualmente. Além disso, seus anúncios passam a ideia de urgência na compra em função de constantes promoções: queima de estoque, limpa loja etc. Já o Mercado faz uma publicidade mais discreta, no seu próprio site, em cartazes colocados nas suas dependências e em anúncios nas rádios locais. As relações com os clientes também são muito distintas. O Mercado, ao comercializar produtos do dia a dia, mas também produtos raros, mantém uma relação de fidelidade e ou pessoalidade com os clientes. Já a loja de eletroeletrônicos disputa seus clientes num mercado muito competitivo, em que o que conta é o preço, uma vez que comercializa produtos de grandes marcas disponíveis em várias outras lojas concorrentes. Sua estratégia comercial tem como foco o preço para o consumidor e ganho de vendas em escala. Outra estratégia da loja é mostrar no seu site a foto do seu proprietário com o seguinte slogan: "Aqui tem dono", transmitindo uma ideia de pessoalidade no atendimento, o que só pode ser interpretado como um simulacro de pessoalidade, impossível de se concretizar em 280 filiais espalhadas pelo País. ${ }^{13}$

\footnotetext{
${ }^{13}$ Estratégia semelhante é utilizada pela rede de cafés Starbucks. Apesar de comercializar em várias partes dos Estados Unidos e nas principais cidades do mundo um produto globalizado e padronizado, seu marketing passa a ideia de originalidade e singularidade, propagandeando a experiência única com cafés de qualidade de várias partes do mundo, em um ambiente descontraído e com atendimento personalizado, que inclui o registro do nome do cliente nos produtos. Como analisa Rippin (2007), trata-se de um simulacro da pessoalidade e da invenção de um lugar.
} 
O que se pretendeu discutir aqui, a partir desse conflito, não foram as lojas em particular, até porque outras semelhantes já existem no Mercado e outras ainda podem vir a se instalar aí. Como se procurou mostrar, a mudança de ramos faz parte da dinâmica do comércio varejista, mas também da história pessoal dos seus proprietários.

O que aconteceu com o espaço que gerou toda essa discussão é representativo também de uma inexorável mudança entre diferentes gerações. O antigo proprietário do armazém, já muito idoso, não estava mais em condições de continuar à frente da sua loja, e seus filhos não manifestaram interesse pelo comércio, uma vez que já estavam envolvidos em outras profissões. Dilema esse também presente nas lojas estudadas por Sharon Zukin, em Amsterdam. Ainda que em contextos diferentes, a rua de lojas sofisticadas de Amsterdam mantém, como as do Mercado, a característica comum de lugares de comércio ancorados em pequenas lojas, muitas delas muito antigas, pertencentes às mesmas famílias e operadas no dia a dia pelos próprios proprietários, mas que, de tempos em tempos, enfrentam problemas de continuidade geracional e a pressão das marcas e das tendências globalizantes. Em 2008, uma loja que, por vários anos, abrigou um comércio de móveis de uma mesma família, foi alugada pelo dobro do preço para a rede de lojas transnacional American Apparel e, em 2012, a Starbucks e mais dois restaurantes de franquia abriram suas lojas na tradicional rua de pequenas e individualizadas lojas (ZUKIN, 2012).

Por fim, cabe concluir a discussão da autenticidade com alguns paradoxos e desafios às políticas patrimoniais, ou seja, com uma conclusão em aberto.

Um desafio, apresentado aqui na forma de uma pergunta, é se a manutenção da diversidade social e do tipo de comércio individualizado presentes no Mercado Central pode depender apenas do seu reconhecimento social contido nas narrativas da autenticidade, ou se é necessária uma proteção oficial. Ainda que o discurso da autenticidade seja apropriado pelos comerciantes como uma forma de defesa desse tipo de comércio, ele é suficiente para se contrapor às forças comerciais das grandes redes e à consequente descaraterização do comércio, da sua sociabilidade e unicidade?

Por outro lado, o fechamento das duas lojas e a divisão do espaço em três podem revelar que o Mercado não é (pelo menos até o momento) um ambiente propício a esse tipo de loja. Do ponto de vista comercial, esse caso mostrou que as lojas de redes são mais rentáveis se situadas em outros 
lugares da cidade do que no interior do Mercado, indicando a continuidade da vocação desse para o pequeno comércio, a diversidade e o turismo.

Apesar de os órgãos governamentais não terem tido sucesso nas suas tentativas de proteção do Mercado, não se deve desconsiderar os efeitos da mobilização da sociedade civil e do próprio estado. As manifestações e a politização da autenticidade não aurática reforçam a manutenção do mercado com a sua diversidade de produtos, comerciantes e públicos, mas não se fecham completamente a algumas mudanças, como as que ocorreram em toda a sua história e, ao que parece, continuarão a ocorrer.

\section{Referências}

ANDRADE, Luciana Teixeira.

(1987). Ordem pública e desviantes sociais em Belo Horizonte (1897-1930). Dissertação de Mestrado apresentada ao Departamento de Ciência Política da Universidade Federal de Minas Geral (UFMG).

ARANTES, Antonio Augusto.

(2009). Sobre inventários e outros instrumentos de salvaguarda do patrimônio cultural intangível: ensaio de antropologia pública. Anuário Antropológico, v. 2007-8, p. 173-222.

BENJAMIN, Walter.

(1980). A obra de arte na época de suas técnicas de reprodução. Os pensadores, 48.

BIDOU-ZACHARIASEN, Catherine.

(2007). De volta à cidade: dos processos de gentrificação às políticas de 'revitalização' dos centros urbanos. São Paulo, Annablume.

BITAR, Nina Pinheiro.

(2016). Projetos urbanísticos, mercados populares e processos de patrimonialização na cidade do Rio de Janeiro. Estudos Históricos, v. 29, p. 261-282, Rio de Janeiro.

BRANT, Fernando.

(2004). Mercado Central. Belo Horizonte, Conceito.

BROMLEY, Rosemary D. F.

(1998). Market-place trading and the transformation of retail space in the expanding Latin American City. Urban Studies, v. 35, n. 8, p. 1.311-33.

COSTA, Eduardo.

(2007). Mercado Central: a convivência entre iguais e diferentes. Belo Horizonte, Editora do Autor.

COSTA, Eduardo.

(2006). Mercado Central de Belo Horizonte: a convivência entre iguais e diferentes. Dissertação apresentada ao Programa de PósGraduação em Ciências Sociais da Pontifícia Universidade Católica de Minas Gerais (UFMG).

FILGUEIRAS, Beatriz Silveira Castro.

(2006). Do mercado popular ao espaço de vitalidade: o Mercado Central de Belo Horizonte. Dissertação de Mestrado apresentada ao Instituto de Pesquisa e Planejamento Urbano e Regional (IPPUR) da Universidade Federal do Rio de Janeiro (UFRJ).

FONSECA, Maria Cecília Londres.

(2003). Para além da pedra e cal: por uma concepção ampla de patrimônio cultural. In: Regina Abreu; Mário Chagas (Org.); Memória e patrimônio: ensaios contemporâneos. Rio de Janeiro, DP\&A Editora. p. 56-76.

GLASS, Ruth.

(1964). Introduction: aspects of change. In: Ruth Glass - Centre for Urban Studies (Ed.); London: Aspects of Change. London, MacGibbon and Kee. 
GOFFMAN, Erving.

(1999). A representação do eu na vida cotidiana.

Petrópolis, Editora Vozes.

GONÇALVES, José Reginaldo Santos.

(2012). As transformações do patrimônio: da retórica da perda à reconstrução permanente. In: Izabela Tamaso; Manuel Ferreira Lima Filho (0rgs.); M. Antropologia e patrimônio cultural: trajetórias e conceitos. Brasília, ABA. p. 59-73.

GONÇALVES, José Reginaldo.

(1988). Autenticidade, memória e ideologias nacionais: o problema dos patrimônios culturais. Revista Estudos Históricos 1 (2), p. 264-275.

HANDLER, Richard.

(1986). Authenticity. Anthropology today, v. 2, n. 1, p. 2-4.

IPHAN.

(2010). Mercado Central: memórias e perspectivas. Belo Horizonte, IPHAN / Tradição Planalto Editora.

LESS, Loreta; SLATER, Tom; WYLY, Elvin. (2008). Gentrification. Nova York, Routledge.

LEITE, Rogério Proença.

(2010). A exaustão das cidades: antienobrecimento e intervenções urbanas em cidades brasileiras e portuguesas. Revista Brasileira de Ciências Sociais v. 25, n. 72, p. 73-88.

MACCANNELL, Dean.

(1973). Staged authenticity: Arrangements of social space in tourist settings. American journal of Sociology 79 (3), p. 589-603.

MULLINS, Paul.

(2012). The Death of Authenticity and the Outsider: Consumption and Hipsters. Disponivel em: https://paulmullins. wordpress.com/2012/12/08/the-death-ofauthenticity-and-the-outsider-consumptionand-hipsters/. Acesso em 10 julho de 2016.

NETTO, Marcos Mergarejo; DINIZ, Alexandre Magno.

(2004). Articulações socioespaciais do Mercado Central de Belo Horizonte. Caderno de
Geografia da PUC - Minas, v. 14, n. 22, p. 7088.

RIBEIRO, Luiz Cesar de Queiroz; SANTOS JUNIOR, Orlando Alves dos.

(2015). Governança empreendedorista e megaeventos esportivos: reflexões em torno da experiência brasileira. In: Orlando Alves dos Santos Júnior; Christopher Gaffney; Luiz Cesar de Queiroz Ribeiro (Orgs.); 0s impactos da Copa do Mundo 2014 e das Olimpíadas. Rio de Janeiro, E-papers.

RIPPIN, Ann.

(2007). Space, place and the colonies: rereading the Starbucks' story. Critical Perspectives on International Business, v. 3, n. 2, p. 136-49.

ROCHA, Gilmar; OLIVEIRA, Silvana Seabra.

(1997). Cidade à deriva. Caderno de Ciências Sociais, v. 5, n. 8, p. 35-65, dez.

RUBIN0, Silvana.

(2009). Enobrecimento urbano. In: Carlos Fortuna; Rogério Proença Leite (Orgs); Plural de cidades: novos léxicos urbanos. Coimbra, Almedina.

SILVA, Diego Vernilleda.

(2015). Mercados municipais de São Paulo: Equipamentos essenciais ou excentricidade urbana? In: Anais do XVI Encontro Nacional da Associação Nacional de Pós-graduação e Pesquisa em Planejamento Urbano (ENANPUR). Belo Horizonte, Brasil.

SLATER, Tom.

(2011). Gentrification of the city. In: Gary Bridge; Sophie Watson (Eds.); The New Blackwell Companion to the City. Blackwell Publishing.

SMITH, Neil.

(1996). The new urban frontier: gentrification and the revanchist city. Londres / New York, Routledge.

TAMASO, Isabela Maria.

(2005). A Expansão do Patrimônio: novos olhares sobre velhos objetos, outros desafios. Série Antropologia, v. 390, p. 1-31. 
TRILLING, Lionel.

(1971). Sincerity and authenticity. Cambridge, Havad University Press.

WATSON, Sophie; STUDDERT, David. (2006). Markets as sites for social interaction. Bristol, Policy Press for the Joseph Rowntree Foundation. Disponivel em: www.jrf.org.uk/ bookshop/eBooks/1940-markets-socialinteraction.pdf. Acesso em 12 de novembro de 2014.

ZUKIN, Sharon.

(2012). The social production of urban cultural heritage: identity and ecosystem on an Amsterdam shopping street. City, Culture and Society, v. 3, p. 281-91.

ZUKIN, Sharon.

(2011). Reconstructing the authenticity of place. Theory and Society, v. 40, p.161-5.

ZUKIN, Sharon. (2010).

Naked city: the death and life of authentic urban places. New York, Oxford University Press.

ZUKIN, Sharon.

(2009). Changing Landscapes of Power: Opulence and the urge for Authenticity. International Journal of Urban and Regional Research, Volume 33.2 June, p. 543-53.

ZUKIN, Sharon.

(2008). Consuming authenticity. From outposts of difference to means of exclusion. Cultural studies, v. 22, n.5, p. 724-48.
Web Sites consultados:

http://www.mercadocentral.com.br/

http://www.casarioverde.com.br/

www.ricardoeletro.com.br

http://eusouatoa.com/

http://www.belohorizonte.mg.gov.br/ categorias/belotur-0

http://www.feriasbrasil.com.br/

http://www.oquesefaz.com/2011/06/24/omercado-central-de-belo-horizonte/

\section{Recebido em}

julho de 2016

\section{Aprovado em}

março de 2017 